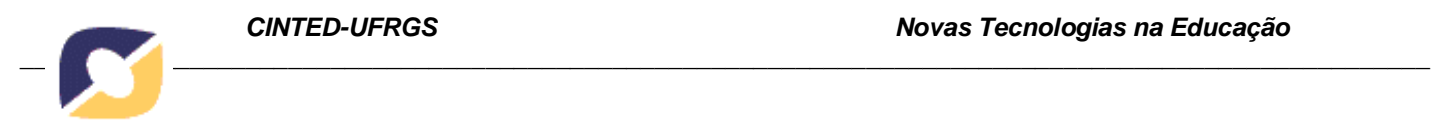

\title{
A Influência dos Enunciados na Construção de Identidades em um Ambiente Virtual de Aprendizagem
}

\author{
Lígia Maria Sayão Lobato Coppetti \\ UniRitter
}

Resumo

Este estudo tem foco na leitura analítica dos enunciados produzidos nas seções do fórum do Ambiente Virtual de Aprendizagem Moodle, pelos alunos do Curso de Licenciatura em Música da UFRGS, na modalidade à distância (EAD). O corpus abrange os alunos matriculados nos polos de Cachoeirinha (RS), Canoinhas, Itaiópolis e São Bento do Sul (SC). Levando em conta a comunicação mediada pelo computador, este trabalho objetiva refletir sobre a influência dos enunciados dos fóruns em relação às Unidades de Estudo (UEs) selecionadas na construção e expressão de identidades dos alunos. A descrição destes enunciados desencadeou uma leitura interpretativa que demonstrou a influência do constante estimulo dado nas UEs à sensibilidade e consequente expressividade desta para a construção e expressão das identidades dos alunos.

Palavras-chave: Ambiente Virtual de Aprendizagem - Enunciados - Identidade

\begin{abstract}
This study focuses on the analytical reading of statements made on forums of the Moodle Virtual Learning Environment by students of the Bachelor of Music at UFRGS, in distance learning (DL). The corpus includes students enrolled at the poles of Cachoeirinha (RS), Canoinhas, Itaiópolis and São Bento do Sul (SC). Taking into account the computer mediated communication, this paper aims to reflect on the influence of the forums listed in relation to the selected Study Unities (SUs) in the construction and expression of students' identities. The description of these statements triggered an interpretative reading which showed the influence of the constant stimulus given in the SUs and the consequent expression of this sensitivity for the construction and expression of the students' identities.
\end{abstract}

Keywords: Virtual Learning Environment - Statements - Identity

Autor: ligia.coppetti@gmail.com

V. $10 \mathrm{~N}^{\mathrm{o}} 1$, julho, 2012 


\section{Comunicação Mediada pelo Computador}

A partir das três ultimas décadas do século XX, aparece um novo tipo de comunicação mediada pelo computador (CMC) ou comunicação eletrônica. Surgem, então, novos gêneros com as novas tecnologias, em particular na mídia eletrônica (digital). A escrita, no entanto, aparece revalorizada, embora com a presença simultânea do áudio e do vídeo no virtual. Dentre esses gêneros, estão os e-mails, os chats, as listas de discussão ou fóruns, os blogs, nos quais a escrita tende à informalidade, com menor monitoração, adequada à fluidez do meio e à rapidez do tempo na interação (MARCUSCHI, 2008, p. 200-202). Neste estudo, os enunciados dos fóruns, postados pelos alunos, em interlocução com os enunciados das Unidades de Estudo, postados pelo professor e pelos tutores, têm sua centralidade como forma de comunicação escrita e consequente interação do grupo de alunos/professores.

Na cultura da virtualidade, os meios digitais buscam se adequar às necessidades e interesses de seu público. Devido às diferenças de cada um, a individualização é uma consequência direta de seu uso (CASTELLS, 2010, p. 422). Aqueles que se utilizam desses meios também o produzem, fornecendo conteúdo e dando forma à rede, tanto em uma comunidade virtual formal (neste AVA) como em uma informal (em uma comunidade de relacionamento). Muitos contribuem para muitos, mas cada um, com sua própria voz, espera uma resposta individualizada (CASTELLS, 2010, p. 439-441), como pôde ser percebido nas formas de apoio, opinião e socialização, nas interlocuções dos fóruns em estudo.

A CMC vem reforçar o hábito milenar de conversar, agora utilizando o meio eletrônico. Na frente da tela do computador, milhares de pessoas, noite e dia, procuram seus pares com os mais diversos propósitos. - seja um motivo pessoal, profissional, educacional, familiar - o que importa é a interação intencional. Cada vez é maior o número de pessoas que se dedicam a esse tipo de comunicação, que pode ser dirigida a outro indivíduo, a um grupo de conhecidos ou de desconhecidos, situados em contextos da vida "real" ou virtual.

Neste estudo, a ferramenta de comunicação foram os fóruns, um recurso assíncrono, baseado nas postagens de tópicos e comentários não realizados em tempo real. Neles os indivíduos participantes têm a possibilidade de planejar suas respostas e postá-las, geralmente de modo mais informal, mesmo se tratando de um ambiente virtual de aprendizagem.

A comunicação eletrônica, pelo encurtamento de distâncias, pela imediatez temporal, pela remoção da fixidez, impõe mudanças na posição e na figura do "eu" (POSTER, p. 60, apud SANTAELLA, 2007, p. 92). Toda simulação que ocorre na realidade virtual tem como consequência comunicações descentralizadas e multiplicação de realidades, constituindo um sujeito instável, difuso e fragmentado, sempre em projeto (idem, p. 30-32, apud p. 92). 
A instabilidade do ciberespaço é um lugar próprio para o desenvolvimento desse sujeito. A identidade já é, por natureza, múltipla. A novidade que a comunicação mediada pelo computador traz é a possibilidade da simulação. Nela é permitido ao indivíduo "brincar" com seu "eu" de novos modos enquanto interage com o "outro" (SANTAELLA, 2007, p. 96-97). Múltiplas identidades são, assim, experimentadas, mesmo que de forma momentânea.

Identidades na cibercultura

Como então se mostram as identidades neste novo espaço? Há hoje um questionamento constante quanto aos modos de viver e de ser, de quem somos. Vivemos uma realidade em que as atividades nas quais nos envolvemos, as identidades que assumimos, mesmo que momentâneas, e as múltiplas informações que recebemos colaboram com esse questionamento, ao disponibilizar a visão de um mundo multicultural que está em nosso cotidiano. Então, identidade passa a ser uma questão central, constante nesse momento de crise, pois se antes era vista como fixa, coerente e estável, hoje está envolta e constituída pela dúvida e pela incerteza. Os conceitos de identidade são um construto central na compreensão das mudanças sociais, políticas, tecnológicas, culturais e econômicas, de acordo com Woodward (1997, apud MOITA LOPES, 2003, p. 17).

Fazendo um comparativo entre a cultura impressa e de interlocução face a face, em sala de aula presencial e a EAD, na cultura digital, percebe-se que anteriormente havia mais elementos que auxiliavam a identificação das identidades dos alunos, como a linguagem verbal escrita, a corporeidade e a oralidade. Hoje, porém, há outros padrões utilizados pelo observador e interlocutor na educação em meio digital, transmitidos e percebidos basicamente através da linguagem verbal escrita e da moldagem consequente das identidades. Esse atual estímulo à liberdade de expressão traz à tona as diferenças, o que remete às múltiplas identidades, ao contrário da cultura impressa, com padrões nos quais submergiam as diferenças.

Houve, nas últimas décadas, uma revolução nas experiências e comunicações interpessoais, principalmente naquelas relacionadas à rede mundial de computadores. Práticas discursivas por meio do correio eletrônico, salas de bate-papo e listas de discussão on-line são exemplos dessas mudanças. Em meio a constantes evoluções tecnológicas, porém, a necessidade de contato humano e de comunicação interpessoal persiste, apesar dessas novas formas de interação.

As transformações linguísticas e visuais de comunicação provocadas pelo atual acesso e uso das TICs (tecnologias de informação e de comunicação) nos levam também à desestabilização de ideias a respeito do que sejam identidades e de que identidades são 




possíveis neste espaço. O ciberespaço, então, com novas linguagens, novas representações, novos modos de interação, também está constituindo novas identidades, novos processos identitários, manifestados e desenvolvidos nas diferentes práticas sociais das quais o indivíduo participa.

Ao contrário das relações face a face, em geral marcadas socialmente, os ambientes virtuais oferecem espaços sem barreiras socioculturais (gênero, classe, etnia, raça, idade), com troca de informações e serviços, contribuindo para desestabilizar identidades cristalizadas e desafiar relações hierárquicas.

A internet se converteu em um "laboratório para a realização de experiências com as construções e reconstruções do 'eu' na vida pós-moderna, uma vez que, na realidade virtual, de certa forma moldamo-nos e criamo-nos a nós mesmos" (GARBIN, 2003, p. 126). Pode-se pensar que o anonimato permite a invenção não apenas de características de personalidade como também de uma descrição física que seja compreendida como atraente e, portanto, uma identidade que facilite, propicie uma aproximação virtual com o outro. Essas identidades "fictícias" criadas pelo próprio indivíduo podem variar de acordo com o momento, o interesse, o estado de humor ou com o destinatário da mensagem. Atrás de uma tela e com um teclado, é solicitada a constituição de identidades àquele que está distante, apenas por ordens de discurso. São indivíduos que se encontram virtualmente transmitindo e compartilhando costumes, atitudes, padrões, valores, crenças, conhecimentos, formas de ser.

Assim, com os recursos da interação virtual, podem ser compreendidas as identidades como multiplicidade, pois há a possibilidade de construir e alternar várias personalidades. Os nicknames, por exemplo, com a escolha de autodenominações modificadas sempre que o usuário o desejar, têm o propósito de marcar as identidades de acordo com o momento. Elas são flexíveis, dependentes de algo fora do "eu", ou seja, da relação com o outro. Segundo Garbin (idem, p. 132-133), o que é mais importante não é saber qual a verdadeira identidade ou o aspecto fictício da pessoa, entendendo-a como algo finalizado, mas como algo em construção, como um momento retratado do indivíduo.

A ausência do contato face a face na internet estimula desinibições, tanto no sentido positivo quanto no negativo. Embora possa haver maior proximidade entre as pessoas, maior mobilidade de identidades, aceitação de experimentação e ambiguidade, ultrapassagem de barreiras de preconceitos, também pode haver provocações e violações.

As identidades no ciberespaço parecem estar ligadas ao conceito de desterritorialização. Como consequência desse processo, novos territórios, novas formas e novos significados surgem, e as interações possibilitam liberdade e emancipação para a criação de identidades múltiplas. Há simultaneamente uma promessa de emancipação e a regulação do já instituído, do social, que está impresso no sujeito que habita o ciberespaço. 


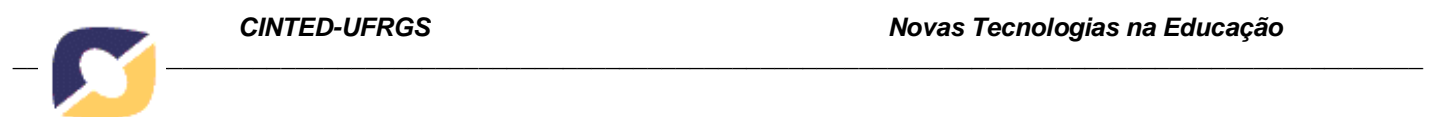

As identidades do indivíduo, nesse espaço, organizam-se em torno de imagens que ele produz. Quanto mais esse indivíduo explorar, contribuir e produzir, participando de intelectuais coletivos, mais identidades ele possuirá no espaço do saber, pluralizando suas identidades, explorando mundos heterogêneos, sendo ele próprio heterogêneo e múltiplo, um "vir-a-ser".

\section{Metodologia}

Este trabalho foi construído com base na leitura das 465 postagens selecionadas nos fóruns da interdisciplina "Repertório Musicopedagógico B" desenvolvida no Ambiente Virtual de Aprendizagem Moodle pelos alunos do Curso de Licenciatura em Música da UFRGS, na modalidade à distância (EAD) Os enunciados no suporte digital constituíram a base para a problematização das expressões identitárias desse grupo de 90 alunos participantes nos fóruns dos quatro polos da região Sul do país (Cachoeirinha/RS e Canoinhas, Itaiópolis e São Bento do Sul/SC). Foram selecionadas neste momento duas Unidades de Estudo (17 e 26) para ser discutida a linguagem verbal mediada pelo computador. Seus fóruns, como um espaço de verbalização e de interação entre alunos, tutores e professor, tiveram seus enunciados analisados em relação àqueles presentes nas suas Unidades de Estudo. $\mathrm{O}$ objetivo era fazer uma análise da influência destes enunciados na construção de identidades do próprio indivíduo e do outro com que interage no grupo em questão.

Conceitos de Bakhtin (2003) sobre o uso da linguagem servem de orientação para esta leitura, embora tenhamos presente que suas teorias não consideram a linguagem no meio digital, praticada somente a partir do final do século XX. Mikhail Bakhtin, em Marxismo e Filosofia da Linguagem (idem), após revisar alguns enfoques históricos da linguística, centra sua atenção no uso da linguagem como comunicação discursiva que envolve o falante e o(s) outro(s) em posição ativa, situados em determinados contextos, do que decorre, na alternância de falas, implicações sócio-históricas.

Nesse sentido, assume importância, nos estudos desse autor, o conceito de enunciado. Este é considerado a "real unidade" da comunicação discursiva e, como tal, presta-se a análises que se direcionam à compreensão das relações humanas, de sua expressão e comunicação. A percepção do enunciado como unidade da comunicação se funda na possibilidade estrutural do estabelecimento de limites de cada enunciado. O que define esses limites é a alternância dos sujeitos no discurso, o qual se inicia com um enunciado do sujeito e se finda com um enunciado - uma compreensão silenciosa ou uma ação responsiva - do outro. $\mathrm{O}$ enunciado sempre termina com a transmissão da palavra ao outro ou a sua compreensão responsiva (idem, p. 275).

A metodologia sugerida por Bakhtin (2009, p. 128-132) segue uma ordem para o estudo do 


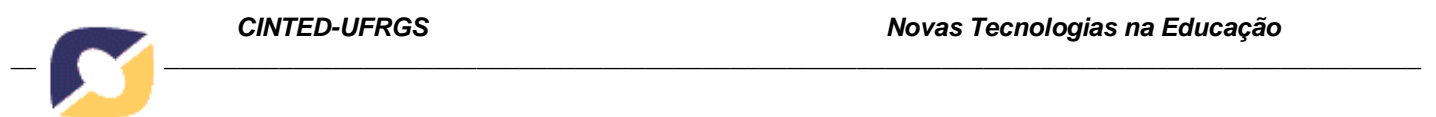

uso da língua: (1) formas e tipos de interação verbal, vista de acordo com o contexto em que ocorre. Se relacionarmos com o contexto em que se deram as interações professor/tutores e alunos no AVA Moodle em estudo, pode ser percebido que os enunciados dos alunos assumiam uma forma no ambiente de aprendizagem e, nas Unidades (enunciados dos professores/tutores), outra, diferente. O passo seguinte deve focar (2) as formas das enunciações "em ligação estreita com a interação de que constituem os elementos" para posterior (3) análise "das formas da língua na sua interpretação linguística habitual".

Embora Bakhtin (2003, p. 272) se refira em geral a falante e ouvinte e, quando em relação à escrita, a textos literários, ele é explícito ao afirmar: "Tudo o que aqui dissemos refere-se igualmente, mutatis mutandis, ao discurso escrito e ao lido". Assim, sua metodologia, ainda que oriunda de uma cultura distinta, torna-se operativa para questionamento e análise dos textos veiculados no meio eletrônico, em situação de aprendizagem EAD, no Ambiente Virtual de Aprendizagem Moodle.

\section{Resultados e Discussão}

Em primeiro lugar foi realizada uma analise da Unidade 17 e seus respectivos fóruns: Esta Unidade estava centrada no processo de criação de uma canção, por parte dos alunos/professores, com finalidade educativa, incluindo as prováveis dificuldades que poderiam ocorrer no seu desenvolvimento, ou seja, o medo e a timidez. Para tanto, fez referência às lembranças da vida escolar de cada um e às suas experiências iniciais de redação de textos para fazer um paralelo com a situação atual, com a atual tarefa a ser cumprida. Ele foi incentivado a se lembrar de uma experiência sua, uma vivência em sala de aula que certamente foi presencial, portanto, de uma cultura predominantemente impressa e de interlocução face a face.

A linguagem da Unidade mostrou-se na forma de estímulo e de orientação aos alunos, trazendo frases de músicos e compositores famosos, como: Stravinsky: a inspiração vem do trabalho; Tom Jobim: música é um produto de 5\% de inspiração e 95\% de transpiração. É verdade; de filósofos como: Kierkegard e Nietzsche, Camus e Sartre afirmam que a coragem não é ausência de desespero, mas a capacidade de seguir em frente, apesar do desespero; ou frases compostas pela própria Unidade: Para o professor a coragem deve vir (e vem) da necessidade de criar para seus alunos; Intensificar a dedicação e o compromisso com a coisa a ser criada é uma forma de promover esse encontro, sendo a criatividade uma consequência.

Assim, percebe-se que a Unidade se apresentou em forma de estímulo ao trabalho do aluno, à liberação da sensibilidade, à produção criativa, valorizando as experiências vividas por 
cada um. A atividade disponibilizada nessa Unidade propôs simulação de jogos enfocando a expressividade em voz e gestos, entonação de voz, na interpretação de distintos personagens do cotidiano. Foi estimulado o trabalho e a troca grupal, embora, ao mesmo tempo, fosse individual, respeitando o ritmo e o momento de cada aluno.

Nessa proposta, houve uma mistura entre o presencial e o virtual, uma vez que as atividades deveriam ser realizadas entre os colegas do polo. Nessas, a expressividade, a fala, os gestos, através do corpo, foram enfatizados e, depois, deveriam ser descritos e discutidos nos fóruns. Entretanto, esses encontros presenciais dos alunos apareceram raramente nas discussões, sem um desenvolvimento que pudesse dar aos leitores a visão do que ocorreu e em que frequência. A interação parece ter ocorrido com mais efetividade no meio digital. Infere-se, também, que as atividades eram realizadas, na maioria das vezes, individualmente e discutidas depois no fórum, conforme os enunciados a seguir:

\begin{tabular}{|l|l|}
\hline $\mathrm{N}^{\circ}$. & Enunciados dos alunos \\
\hline 21. & $\begin{array}{l}\text { "Colegas, para mim não é simples fazer uma composição, mas vou } \\
\text { procurar ler mais ouvir ainda mais musica e tendências procurando ser } \\
\text { coerente principalmente amadurecer as idéias de musica escrevendo com } \\
\text { o se fosse uma historia com principio e meio e por ai vai nascendo minha } \\
\text { canção. Bons estudos. }\end{array}$ \\
\hline 172. & $\begin{array}{l}\text { "Ainda não consegui me reunir com os colegas do pólo de Itaiópolis. A } \\
\text { princípio farei uma pesquisa sobre o coelho, pois é um animal esperto e } \\
\text { rápido, e alem disso acho muito fofo. Porem assim que conversar com os } \\
\text { colegas, darei essa sugestão, bem como reuniremos as sugestões do grupo } \\
\text { para decidirmos em que animal iremos nos inspirar"; }\end{array}$ \\
\hline 286. & $\begin{array}{l}\text { "Tanto nos solfejos como na composição da canção achei que não } \\
\text { conseguiria, sempre tive dificuldades com solfejos e nunca compus uma } \\
\text { canção. Estou muito feliz por ter realizado as duas coisas"; }\end{array}$ \\
\hline 395. & $\begin{array}{l}\text { "O solfejo no começo assustou um pouco, mas depois estudando juntos, } \\
\text { devagar, fomos solucionando as dúvidas, arrumando os erros, e vimos como } \\
\text { é bom solfejar. Sou professora do Método Suzuki, e solfejos as músicas com } \\
\text { as crianças para elas gravarem melhor a melodia e o ritmo. Devagar } \\
\text { chegaremos lá!”; } \\
\text { "Obrigada pelos comentários! Achamos uma ótima forma de começarmos } \\
\text { aprender a compor. É muito legal esta interação que estamos tendo pelo } \\
\text { fórum, assim podemos ouvir uns aos outros e cada vez aprendermos e } \\
\text { melhorarmos mais!" }\end{array}$ \\
\hline 320.
\end{tabular}

QUADRO 1 - Enunciados de alunos relativos à Unidade 17

Fonte: dados da pesquisa de campo 


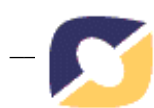

Obs.: grifos da autora.

Nos enunciados selecionados, acima expostos, pode ser percebido que, embora o esforço pessoal na execução da tarefa de uma construção musical fosse muito importante, o apoio do grupo foi essencial. Expressões como "para mim não é simples fazer uma composição, mas vou procurar ler mais ouvir ainda mais musica", "no começo assustou um pouco... mas estudando juntos... devagar chegaremos lá", "podemos ouvir uns aos outros... aprendermos e melhorarmos mais", demonstram esse fato.

Os estímulos expressos na Unidade buscavam provocar a expressão da sensibilidade e da criatividade, evidenciando um contorno de identidades. Padrões foram transmitidos, percebidos e, assim, moldam-se identidades. Embora a construção da canção tenha sido individual, levando em conta a sensibilidade de cada um, a opinião, aceitação, o apoio e incentivo do outro foram relevantes para a expressividade. Também a socialização das experiências vividas pôde influenciar e, até mesmo determinar o caminho de uma produção criativa. É o que pode ser percebido nos enunciados aqui selecionados.

Sabe-se que o pensamento e sua expressão no dia a dia são formados por conteúdos ideológicos, determinados pela vivência no social. Podemos dizer que esses alunos/professores, tanto ao comporem suas canções como ao ouvirem e comentarem as de seus colegas estavam buscando aspectos da sua atividade mental e expressando-a através de referências sociológicas, ligadas ao seu cotidiano. A visão e a percepção de mundo de cada um deles se refletiram nos enunciados enquanto buscavam construir sua canção. Eles buscavam marcar suas identidades através da expressão de seus pensamentos, fato constantemente estimulado nas Unidades.

Em um segundo momento foi realizada uma analise da Unidade 26 e seus respectivos fóruns: Nessa Unidade, o foco foi a voz e as técnicas vocais. Foi enfatizado o uso consciente da voz em todas as nuances, a importância do aspecto fisiológico e psicológico, principalmente do autoconhecimento. É imprescindível que primeiramente o professor (intérprete) esteja sensibilizado e que esteja completamente a vontade com o seu próprio ser!; A voz é também um código de expressão da alma, pois revela nossas impressões mais profundas através de seu timbre, seu volume, sua forma de emissão, enfim; Assim sendo, falar/cantar e escutar é uma espécie de toque absoluto; O professor usa seu corpo como meio de expressão. Cantar é compreendido como uma expressão da alma, uma espécie de toque, conforme trata a Unidade. Nos fóruns os alunos se expressaram como:

\begin{tabular}{|l|l|}
\hline $\mathrm{N}^{\mathbf{o}}$. & Enunciados dos alunos \\
\hline 337. & $\begin{array}{l}\text { Concordo plenamente com vice Ra. Pois na escola o canto tem que ser } \\
\text { encarado como Integração e Inclusão Social, bem como você disse. Pois a } \\
\text { criança que tem dificuldade com afinação e tal, certamente participando }\end{array}$ \\
\hline
\end{tabular}




\begin{tabular}{|c|c|}
\hline \multirow{2}{*}{0} & Novas Tecnologias na Educação \\
\hline & $\begin{array}{l}\text { de um meio musical, terá grande chance de se desenvolver. A solução } \\
\text { não é excluir e sim incluir. }\end{array}$ \\
\hline 355. & $\begin{array}{l}\text { Concordo que no espaço escolar e durante o período de aprendizagem não } \\
\text { deveria existir a seleção de vozes, pois acho que é um direito de todos } \\
\text { tentarem cantar, assim como é aprender português, matemática, etc. agora } \\
\text { quando se pretende montar um coro com um objetivo específico, eu acho } \\
\text { que é fundamental a classificação das vozes, se não foge de seus } \\
\text { objetivos, seria mais ou menos como alguém que detesta português fazer } \\
\text { poesia. }\end{array}$ \\
\hline 365 & $\begin{array}{l}\text { Gostei de sua colocação caro colega o professor precisa ser conhecedor da } \\
\text { sua arte e principalmente de seu aluno que está ali para cantar e se realizar } \\
\text { independente se abe ou não cantar mais o que importa é a participação, as } \\
\text { técnicas de voz, afinação e expressão virão com o tempo. }\end{array}$ \\
\hline
\end{tabular}

QUADRO 2 - Enunciados de alunos relativos à Unidade 26

Fonte: dados da pesquisa de campo

Obs.: grifos da autora.

Pode ser percebido nas expressões dos alunos, tais como: "a criança que tem dificuldade com afinação... terá grande chance de se desenvolver...”; “eu acho que é fundamental a classificação das vozes..."; "o que importa é a participação, as técnicas de voz, afinação e expressão virão com o tempo", que os alunos focaram e discutiram a importância da voz e sua afinação, mesmo sendo contrários à seleção para corais escolares. Esses se mostraram aspectos relevantes na qualidade de seu trabalho.

É destacada a importância do estimulo à sensibilidade e sua expressividade para a construção de identidades do próprio individuo e do outro com que interage. A constância deste nos enunciados em ambas as Unidades é percebida com resultado nos seus fóruns. A atenção às vivências de cada um e às individualidades são formas de desenvolver a sensibilidade dos alunos no olhar para si e para o outro, sendo esta última materializada na criatividade. Nesse processo, sentidos se unem em prol da percepção de uma nova realidade, através de signos: sejam palavras, sons, imagens. Nesse estudo, então, locutor e ouvinte/leitor em interlocução, oferecem suas palavras, aguardando a compreensão responsiva do outro, enquanto constituem suas identidades, tendo o outro com um referencial. Enquanto se olham, se percebem, se constituem.

\section{Considerações finais}

Pelas possibilidades de expressão e de expansão no meio digital, novas identidades configuravam-se, mostravam-se em uma rede em constante mutação, em um fluxo contínuo 


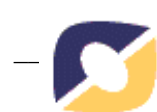

que se retroalimentava com a participação dos usuários. Nesse novo cenário, já não havia mais centralização. O indivíduo, fragmentado, apresentava-se de diversas maneiras, de acordo com o momento, o contexto, com o meio, com os outros com quem interage. As múltiplas identidades presentes em cada indivíduo se tornavam mais evidentes com o uso das tecnologias digitais. Era a fragmentação que passava a ser percebida, como uma consequência das transformações socioculturais dos últimos anos.

Os indivíduos do grupo em estudo estavam vivenciando duas identidades simultaneamente, entre outras, de acordo com as necessidades, interesses, interações e o contexto em que se inserem. Estavam em um espaço físico de sua experiência como docentes e também em um espaço virtual de aprendizagem, como alunos de EAD. Consideremos, porém, que cada uma dessas identidades assumidas possui uma prática discursiva distinta da outra. No caso da identidade de aluno e de músico, o centro do discurso é o próprio indivíduo e, no caso da identidade de professor, o centro do seu discurso é o outro - o aluno. Sua dupla posição tornou-se mais complexa pelo movimento de vai e vem entre predominâncias culturais como professores estavam imersos, agiam e reagaim, numa cultura basicamente oral e escrita, impressa; e, na posição de alunos, no Ambiente Virtual de Aprendizagem Moodle, eram agentes e interlocutores em uma cultura digital, com peculiaridades que a torna específica em termos de interlocução, de processo de aprendizagem, de manifestação e expressão.

Sabe-se que, devido ao crescimento da internet e sua popularidade, ampliam-se as redes de contato, tanto virtuais como presenciais, globais e locais. No caso de um grupo de aprendizagem on-line, era relevante o desenvolvimento da sensação de comunidade, de pertencimento entre seus membros, para que seu desempenho educacional fosse efetivo. Nesse aspecto, também pôde ser percebida a importância das repetições, das concordâncias, apoios, trocas e mesmo das discordâncias no seu desenvolvimento enquanto grupo. Cada uma delas representava uma forma de pertencimento

Percebeu-se que, em um ambiente virtual, as comunicações dão-se de "um para todos" e "todos para todos", em diversas direções. Não era mais característica da comunicação ser "um para um", apenas em um sentido, como anteriormente à era digital. Um aluno hoje posta uma mensagem nos fóruns que é recebida por todos os outros, que respondem igualmente, de modo aberto a todos. Não há um espaço delimitado individual, mas sim um contorno grupal.

As identidades, com a comunicação mediada pelo computador, tendem a interconectadas se mesclarem e se complementarem umas a outras com suas individualidades múltiplas no ciberespaço. Neste ambiente virtual de aprendizagem, pode ser percebido que a sensibilidade no olhar para si e para o outro e sua expressividade, materializada na criatividade, ambas estimuladas na comunicação virtual influenciou a expressão e 


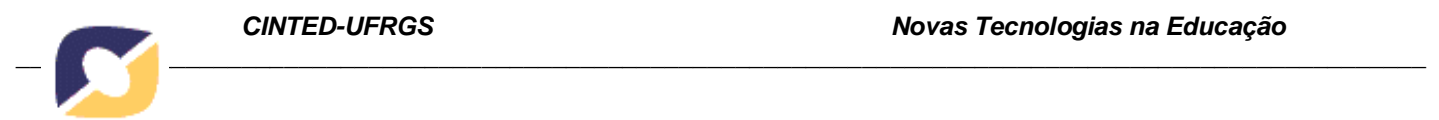

construção de Identidades dos participantes.

Bibliografia

BAKHTIN, Mikhail (Volochínov). Marxismo e filosofia da linguagem. 13. ed. São Paulo: Hucitec, 2009.

. Estética da criação verbal. São Paulo: Martins Fontes, 2003.

CASTELLS, Manuel. A sociedade em rede. A era da informação: economia, sociedade e cultura. São Paulo: Paz e Terra, 2010.

GARBIN, Elisabete Maria. Cultur@s Juvenis, Identid@des e Internet: questões atuais. Revista Brasileira de Educação, Rio de Janeiro, n. 23, 2003. Disponível em: <http://www.scielo.br/pdf/rbedu/n23/n23a08.pdf>. Acesso em 07/2009.

MARCUSCHI, Luiz Antônio. Produção textual, análise e gêneros e compreensão. São Paulo: Parábola, 2008.

MOITA LOPES, Luis Paulo. Socioconstrutivismo: Discurso e identidades sociais. In: MOITA LOPES, Luis Paulo (org.). Discursos de identidade. Discurso como espaço de construção de gênero, sexualidade, raça, idade e profissão na escola e na família. Campinas: Mercado de Letras, 2003. p. 13-38.

SANTAELLA, Lúcia. Linguagens líquidas na era da modernidade. São Paulo: Paulus, 2007. 